\title{
Synthesis and characterization of dialdehyde cellulose nanofibers from O. sativa husks
}

\author{
Edwin Shigwenya Madivoli ${ }^{1}$. Patrick Gachoki Kareru ${ }^{1}$. Anthony Ngure Gachanja ${ }^{1}$. Samuel Mutuura Mugo ${ }^{2}$. \\ David Sujee Makhanu ${ }^{3}$
}

๑) Springer Nature Switzerland AG 2019

\begin{abstract}
Periodate oxidation of cellulose breaks the $\mathrm{C}_{2}-\mathrm{C}_{3}$ bond of the glucose repeating units forming two vicinal aldehyde groups that are amenable to further reactions. In this article, effects of reaction conditions during the oxidation such as reaction time, oxidant concentration, and temperature on the aldehyde content were investigated and an optimized reaction condition identified. The synthesis of 2,3-dialdehyde cellulose (DAC) was confirmed by scanning electron microscopy, transmission electron microscopy (TEM), Fourier-transform infra-red spectroscopy (FT-IR), differential scanning calorimetry, thermal gravimetric analysis and wide-angle X-ray diffractometer (WXRD). Formation of dialdehyde cellulose (DAC) was confirmed by the appearance of carbonyl peak in FT-IR spectra while a decrease in crystallinity of the fibers as a result of oxidation was confirmed by WXRD. Morphological changes during oxidation were observed using SEM while the size of the fibers was confirmed by TEM, which showed the average length of the fibers decreased after oxidation as compared to native cellulose. Thermal degradation studies revealed that oxidation of cellulose decreased the thermal stability of the polymer as compared to native cellulose and was dependent on the aldehyde content. In conclusion, oxidation of native cellulose to dialdehyde cellulose had a profound effect on the thermal stability, degree of crystallinity, size and morphology of the polymer.
\end{abstract}

Keywords CNF·Dialdehyde cellulose $\cdot \mathrm{SEM} \cdot \mathrm{TEM} \cdot \mathrm{XRD} \cdot \mathrm{FTIR}$

\section{Introduction}

Cellulose, a linear polysaccharide comprising of glucose units cross linked with $\beta-1,4-$ glycosidic bonds, is one of the most abundant and renewable natural resource [1]. It is held together by a network of inter and intramolecular hydrogen bonds as well as van der Waals forces which enhances its mechanical properties thereby finding applications as fabric, paper, boards, and in biomedical field such as dressing [2-4]. As such, there is need to take advantage of cellulose intrinsic properties which include reactivity, lightness, biodegradability, and biocompatibility, to synthesize cellulose derivatives. The hydroxyl groups present on the surface of cellulose are often subjected to different chemical treatments such carboxymethylation, methylation, hydroxyethylation, 2,2,6,6-Tetramethylpiperidine 1-oxyl (TEMPO) oxidation and peroxidation [5]. When reacted with periodate ions $\left(\mathrm{IO}_{4}^{-}\right)$at given reaction conditions, the ions cleave the $\mathrm{C}_{2}-\mathrm{C}_{3}$ bonds of the anhydroglucose units (AGU) thereby converting hydroxyl groups present at these two positions into aldehyde groups [4, 6]. As a result, the amorphous regions of cellulose chains

Electronic supplementary material The online version of this article (https://doi.org/10.1007/s42452-019-0769-9) contains supplementary material, which is available to authorized users.

Edwin Shigwenya Madivoli, edwinshigwenya@gmail.com | ${ }^{1}$ Chemistry Department, Jomo Kenyatta University of Agriculture and Technology, P. O Box 62,000-00200, Nairobi, Kenya. ${ }^{2}$ Chemistry Department, McEwan University, 10700-104 Avenue, Edmonton, AB T5J 4S2, Canada. ${ }^{3}$ Department of Physical and Biological Sciences, Karatina University, P. O Box 1957-10101, Karatina, Kenya. 
can be penetrated thereby creating dialdehyde chains and in-turn the remaining ends of the crystalline regions are usually cleaved. Moreover, with sufficient oxidation of cellulose, 2,3-dialdehyde cellulose has been reported to be soluble in hot water making it more susceptible to further functionalization into primary $\left(\mathrm{R}^{1}-\mathrm{CH}=\mathrm{NH}\right)$ or secondary aldimines $\left(R^{1}-C H=N-R^{2}\right)$ and Schiff bases $\left(R^{1}-C R^{3}=N-R^{2}\right)$ [6]. This makes dialdehyde cellulose an interesting candidate for covalent immobilization of high molecular weight nitrogenous compounds such as polypeptides and proteins such as antibodies, enzymes, gelatin, collagen and chitosan [6-8]. Immobilization of these nitrogenous compounds can be employed in waste water treatment [9], wound dressings [10], biochemical sensors [11], drug delivery [12], surgical materials [13], and tissue scaffolds [14]. The aim of this study was to investigate changes that occur in cellulose extracted from rice husks after periodate oxidation for the preparation of films with potential application in wound dressings. Fourier-transform infrared spectrophotometer (FTIR) was used to determine the functional groups present while the degree of crystallinity of oxidized cellulose fibers were determined using wide-angle X-ray diffractometer. The thermal property of the oxidized cellulose was determined using a differential scanning calorimeter (DSC) and thermal gravimetric analyzer (TGA) while surface morphology and size of the fibers were evaluated using a Scanning electron microscope (SEM) and a Transmission electron microscope (TEM) respectively.

\section{Materials and methods}

\subsection{Periodate oxidation of cellulose pulp}

Microcrystalline cellulose (MCC) was extracted from risk husks according to a previous reported method [15]. Periodate oxidation of MCC from rice husks was performed as described elsewhere with minor modifications [16-18]. Typically, $1.0 \mathrm{~g}$ of cellulose was soaked in $50 \mathrm{~mL}$ MilliQ water for $1 \mathrm{~h}$ followed by dispersion in an ultrasonic bath (Telasonic TPC 25, TELSONIC AG, Bronschhofen, Switzerland). Different concentrations of $\mathrm{KIO}_{4}(0.43-6.08 \mathrm{mmol} / \mathrm{g}$ $\mathrm{CE})$ and $\mathrm{KCl}(6.04 \mathrm{mmol})$ were dissolved in water and added to the solution of wet pulp followed by addition of isopropanol $(10 \% \mathrm{v} / \mathrm{v})$ to act as a free radical scavenger $[19,20]$. In order to evaluate effects of different reaction conditions on oxidation, the reaction vessel was wrapped with an aluminum foil and the oxidation performed at different temperatures $\left(25,50,75^{\circ} \mathrm{C}\right)$, oxidant dosage (0-6.06 mmol/g CE) and different reaction time (0.5-24 h). At the end of the reaction, ethanol was added into the reaction vessel to quench the residual periodate and the residue washed with water to neutral $\mathrm{pH}$. The residue was solvent exchanged with ethanol and frozen with liquid nitrogen before lyophilization [16, 21, 22].

\subsection{Determination of aldehyde content}

The aldehyde content was determined by the hydroxylamine hydrochloride method after quantitative reaction between the carbonyl groups and hydroxylamine hydrochloride. In brief, $0.1 \mathrm{~g}$ of oxidized cellulose was mixed with $25 \mathrm{~mL}$ of $0.2 \mathrm{M}$ hydroxylamine hydrochloride solution at $\mathrm{pH} 3$ and stirred for $3 \mathrm{~h}$. The mixture was then back titrated to $\mathrm{pH} 3$ using a $0.01 \mathrm{M} \mathrm{KOH}$ solution. A blank measurement was performed similarly with non-oxidized as-prepared cellulose and the aldehyde content determined from Eq. (1):

Aldehyde content $=\frac{\left(\mathrm{V}_{\mathrm{s}}-\mathrm{V}_{\mathrm{b}}\right) \times \mathrm{C}_{\mathrm{NaOH}}}{\mathrm{M}_{\mathrm{C}}}$

where $\mathrm{V}_{\mathrm{S}}$ and $\mathrm{V}_{\mathrm{B}}=$ volume of sample and the blank while $\mathrm{C}_{\mathrm{NaOH}}$ and $\mathrm{m}_{\mathrm{C}}$ are the concentration of $\mathrm{NaOH}$ solution and the weight of the dry cellulose sample respectively [ $[18$, 21].

\subsection{Characterization of dialdehyde cellulose}

The functional groups present in the reaction products were analyzed by a Bruker Tensor II Fourier Transform Infrared spectrophotometer (Bruker, Ettlingen, Germany). The $\mathrm{KBr}$ pellets were prepared by grinding $10 \mathrm{mg}$ of samples with $250 \mathrm{mg} \mathrm{KBr}$. The pellets were prepared in a standard device under a pressure of $75 \mathrm{kN} / \mathrm{cm}^{2}$ for $3 \mathrm{~min}$. The spectral resolution was set at $4 \mathrm{~cm}^{-1}$ and the scanning range from 400 to $4000 \mathrm{~cm}^{-1}[23,24]$. The crystallinity index of the oxidized fibers was identified using STOE STADIP $P$ X-ray Powder Diffraction System (STOE \& Cie GmbH, Darmstadt, Germany). The $X$-ray generator was equipped with a copper tube operating at $40 \mathrm{kV}$ and $40 \mathrm{~mA}$ and irradiating the sample with a monochromatic CuKa radiation with a wavelength of $0.1542 \mathrm{~nm}$. XRD spectra was acquired at room temperature over the $2 \theta$ range of $5^{\circ}-60^{\circ}$ at $0.05^{\circ}$ intervals with a measurement time of $1 \mathrm{~s}$ per $2 \theta$ intervals $[25,26]$. Differential Scanning Calorimetry (DSC) and Thermal Gravimetric analysis were carried out using a Mettler Tolledo DSC/TGA 3+ system (Mettler-Toledo GmbH, Switzerland). All the samples $(10 \mathrm{mg})$ were heated from 25 to $500^{\circ} \mathrm{C}$ at $10^{\circ} \mathrm{C} / \mathrm{min}$ and cooled to $25^{\circ} \mathrm{C}[23,27]$. Morphology of dialdehyde cellulose was evaluated using Tescan Mira3 LM FE scanning electron microscope (TESCAN ORSAY Holdings, Czech Republic) operated at an accelerating voltage of $30 \mathrm{kV}$. The samples were gold sputtered 
before observation to avoid charging effect [28]. TEM analysis was performed on a Tecnai G2 Spirit (Thermofischer scientific, Oregon USA) operated at $120 \mathrm{kV}$ equipped with veleta $2048 \times 2048$ wide angle and Eagle $4096 \times 4096$ bottom mount detectors. The cellulose was suspended in ultrapure water ( $18 \mathrm{M} \Omega \mathrm{cm}$ Barnstead Genpure UV-TOC, Thermoscientific, Germany) and ultrasonicated to obtain a solution of suspended fibers. The individual solutions were then drop casted in carbon films 300 mesh (Electron microscopy science, CF300-CU) and dried to evaporate the solvent before TEM analysis.

\section{Results and discussion}

\subsection{Effect of oxidant concentration, temperature and time on oxidation}

The rate of cellulose oxidation to 2,3-dialdehyde cellulose (DAC) was dependant on oxidant concentration, temperature and time of the reaction. Beyond $50^{\circ} \mathrm{C}$, the periodate ion decomposed to liberate iodine which in turn has been reported to participate in side reaction with cellulose [6]. However, at room temperature the conversion of cellulose to dialdehyde cellulose proceeds via longer reaction time $(<19 \mathrm{~h})$ which leads to production of $\mathrm{IO}_{3}{ }^{-}$ions that are precipitated as $\mathrm{XIO}_{3}$ when an organic solvent such as ethanol or acetone is used to wash the oxidized cellulose (Figure S4) $[4,21]$. Such side products act as impurities that need to be eliminated during synthesis of DAC hence care should be taken to eliminate them [4]. Maximum reaction temperature used in this study was thus maintained at $50{ }^{\circ} \mathrm{C}$ as at the selected temperature, the reaction time was reduced considerably, and less iodine crystals were formed in the reaction [6]. Moreover, higher temperature leads to decomposition of periodate which leads to lower aldehyde content due to lower reaction efficiency and undesirable side products. On the other hand, increase in oxidant concentration resulted to a subsequent increase in the aldehyde content but this led to an overall decrease in the amount of oxidized cellulose after the reaction (Figure S1).

\subsection{Determination of aldehyde content}

The degree of oxidation was determined by hydroxyl amine hydrochloride and the results are depicted in Table 1.

Periodate oxidation is a function of time, oxidant concentration, temperature and to a smaller extent the source of cellulose. While most authors have used the same source of cellulose i.e. wood pulp for the synthesis of dialdehyde cellulose few have explored the synthesis of
Table 1 Periodate oxidation conditions used for the synthesis of dialdehyde cellulose and corresponding degree of oxidation (DO)

\begin{tabular}{lllll}
\hline Sample & $\begin{array}{l}\mathrm{KIO}_{4}: \mathrm{CE} \\
(\mathrm{mmol} / \mathrm{g})\end{array}$ & $\begin{array}{l}\text { Reaction } \\
\text { time }(\mathrm{h})\end{array}$ & Yield (\%) & $\begin{array}{l}\text { Aldehyde con- } \\
\text { tent }(\mathrm{mmol} / \mathrm{g})\end{array}$ \\
\hline S1 & 0.43 & 16 & $64.4 \pm 0.5$ & $0.25 \pm 0.03$ \\
S2 & 0.87 & 16 & $77.2 \pm 1.0$ & $0.43 \pm 0.01$ \\
S3 & 1.73 & 16 & $72.6 \pm 0.8$ & $1.07 \pm 0.01$ \\
S4 & 2.61 & 16 & $71.4 \pm 0.2$ & $1.55 \pm 0.02$ \\
S5 & 3.48 & 16 & $66.8 \pm 1.0$ & $1.99 \pm 0.03$ \\
S6 & 4.35 & 16 & $67.6 \pm 0.7$ & $2.84 \pm 0.02$ \\
S7 & 5.22 & 16 & $69.1 \pm 2.0$ & $2.34 \pm 0.01$ \\
S8 & 6.09 & 16 & $64.4 \pm 0.1$ & $3.80 \pm 0.02$ \\
\hline
\end{tabular}

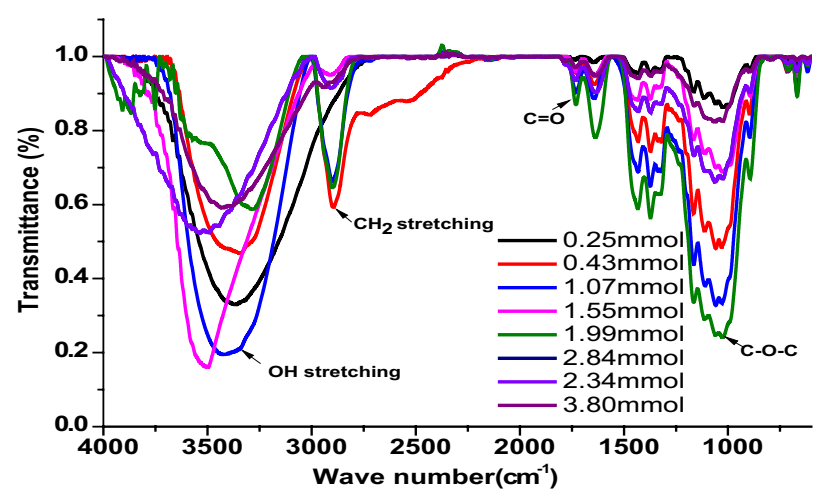

Fig. 1 FT-IR spectra of dialdehyde cellulose with different aldehyde content

DAC from other sources [4, 21, 29]. In our study, 2,3-dialdehyde cellulose was synthesized from microcrystalline cellulose (MCC) that was extracted from O. sativa husks though the present work didn't make comparison with DAC from cotton linters or wood derived cellulose. One notable observation was that oxidation of microcrystalline cellulose followed a somewhat similar trend to what is in literature in that, the oxidation was highly dependent on the amount of oxidant used with higher degree of oxidation (DO) being observed at higher oxidant to cellulose ratios. Moreover, at higher oxidant to cellulose concentrations, the percent yield also decreased which is an indication that higher oxidant concentration led to cleavage of the crystalline bonds in cellulose (Figure S1). This resulted to a more amorphous material recovered at the end of the oxidation reaction as observed in XRD profile and clear cellulose dispersion after the reaction $[4,6,29]$.

\subsection{FT-IR characterization}

The changes in chemical structure during oxidation were examined by FT-IR and the results are depicted in Fig. 1. 
From the spectrum obtained (Fig. 1 and Figure S3), conversion of cellulose to dialdehyde cellulose could be confirmed by the presence of carbonyl vibrational frequency at $1722 \mathrm{~cm}^{-1}$. The absorption peaks at 3300 , $2900,1600,1100 \mathrm{~cm}^{-1}$ were attributed to the vibration frequency of $\mathrm{OH}$ stretching, $\mathrm{CH}_{2}$ stretching, $\mathrm{OH}$ bending vibrations and $\mathrm{C}-\mathrm{O}$ stretching respectively while the peaks at 1376 and $1021 \mathrm{~cm}^{-1}$ were attributed to $\mathrm{CH}_{2}$ bending and $\mathrm{C}-\mathrm{O}-\mathrm{C}$ stretching vibrations $[6,15]$. Oxidation of cellulose by periodate ion is selective to $C_{2}$ and $C_{3}$ carbon atoms alone hence an $\mathrm{OH}$ vibration frequency of the $\mathrm{C}_{6}$ carbon can be observed in the IR spectrum though the intensity decreased with a subsequent increase in the oxidant concentration. This is an indication that $\mathrm{C}_{6} \mathrm{OH}$ group in dialdehyde cellulose isn't oxidized by periodate hence leaving room for further functionalization of dialdehyde cellulose $[4,10,29]$. Subsequently, the aldehyde vibrational frequency observed at $1722 \mathrm{~cm}^{-1}$ increased with a subsequent increase in the oxidant concentration until it reached the cellulose to oxidant concentration of $3.48 \mathrm{mmol} / \mathrm{g}$ cellulose, after which the vibrational frequency started to decrease (Fig. 2). Moreover, the aldehyde vibrational frequency was monitored to evaluate the influence of reaction time on the oxidation of cellulose. The results obtained indicate that the aldehyde vibration frequency increased with increase in reaction time which is an indication that with increase in time more $\mathrm{OH}$ groups were converted to aldehyde $\mathrm{C}=\mathrm{O}$ group [4]. However, longer reaction time led to disappearance of the $C=0$ vibrational frequency which might be as a result of side products forming with increased reaction time as $C=0$ intensity declined at higher reaction time $(>16 \mathrm{~h}$, Figure S4) [4].

\subsection{DSC thermogram}

The DSC thermograms of dialdehyde cellulose are depicted in Fig. 3.

It was observed that the DSC curve for cellulose fibers exhibited two endothermic peaks, a broad peak centered at $108.5^{\circ} \mathrm{C}$ corresponding to water loss and a sharp peak centered at $339.9{ }^{\circ} \mathrm{C}$ corresponding to cellulose

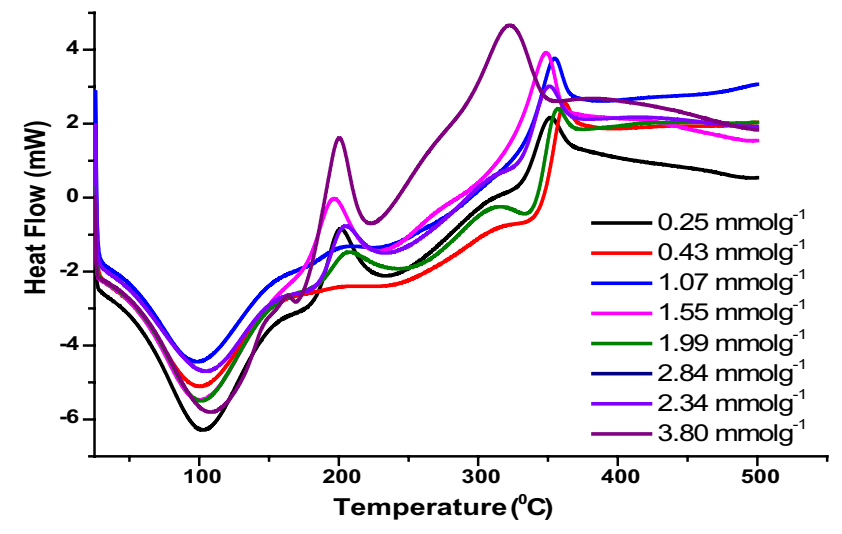

Fig. 3 DSC thermograms of cellulose oxidized with varying amounts of periodate ion

decomposition $\left(\Delta \mathrm{H}_{\mathrm{g}}=33.93 \mathrm{~J} / \mathrm{g}\right)$ [15]. The DSC thermogram of dialdehyde cellulose with different DO were similar to that of cellulose but the peak at $339.9^{\circ} \mathrm{C}$ became increasingly shorter and smaller [30]. These samples possessed two endothermic peaks between 120 and $220^{\circ} \mathrm{C}$ and three exothermic peaks between 188 and $302^{\circ} \mathrm{C}$ with a subsequent disappearance of the endothermic peak centered at $339.9^{\circ} \mathrm{C}$ present in native cellulose thermogram. The disappearance of this peak centered at $339.9^{\circ} \mathrm{C}$ (Figure S5) was attributed to the destruction of the ordered structure of cellulose during oxidation that reduced the crystallinity as reported elsewhere [30]. The loss of crystallinity due to ring opening of AGU during oxidation of cellulose disrupts cellulose ordered structure leading to formation of two new exothermic peaks in DSC curves of periodate oxidized cellulose when $C_{2}-C_{3}$ bond are cleaved during oxidization of MCC [31]. In TGA thermogram of oxidized fibers (Fig. 4 and Figure S6), three degradation stages which correspond to evaporation of adsorbed water $\left(10-130^{\circ} \mathrm{C}\right)$, thermal degradation of oxidized cellulose $\left(150-360^{\circ} \mathrm{C}\right)$ and another degradation that appeared at $480^{\circ} \mathrm{C}$ were observed. Oxidation of cellulose leads to a variation in the structure, crystallinity, and degree of polymerization, which in turn affect its physical and chemical properties [32]. Moreover, periodate oxidation of cellulose

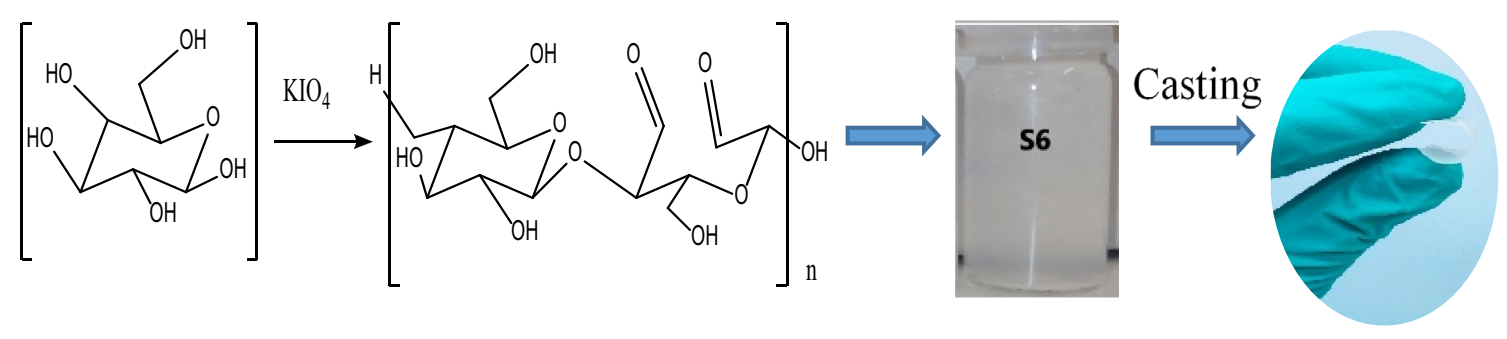

Fig. 2 Schematic synthesis of DAC films from cellulose dispersion 


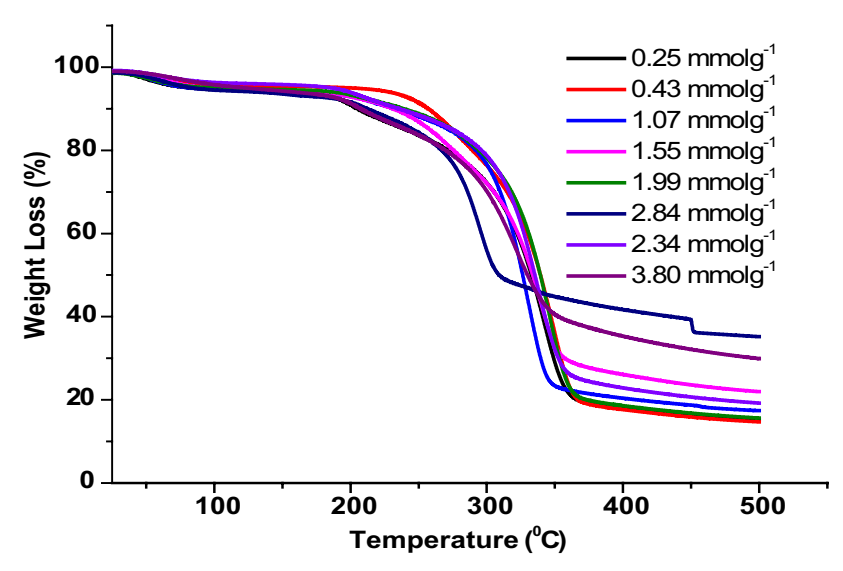

Fig. 4 TGA thermograms of cellulose oxidized with varying amounts of periodate ion

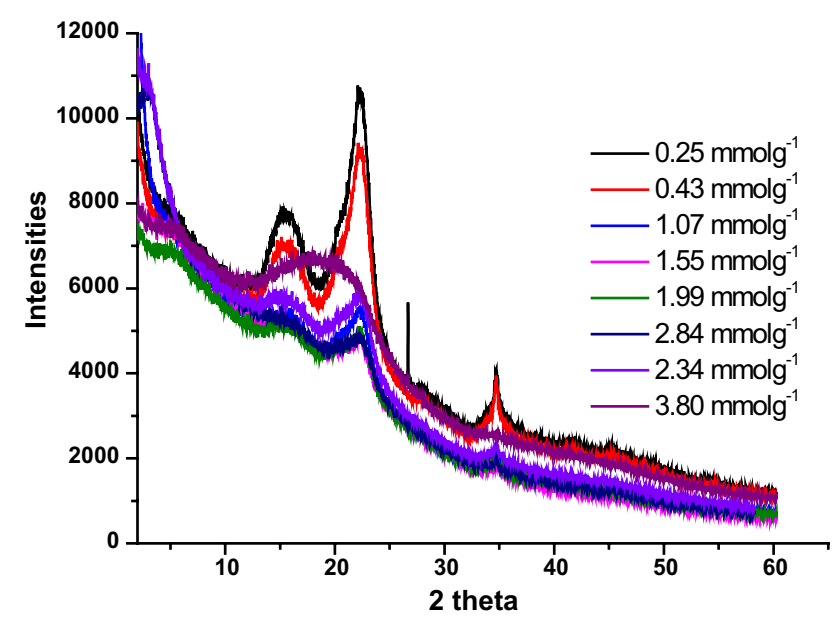

Fig. 5 Changes in X-ray pattern of cellulose induced by periodate oxidation

alters the physical and chemical properties of cellulose, imparts antimicrobial activity to the oxidized fibers against Staphylococcus aureus and results in improved biocompatibility with mammalian cells [32].

\subsection{X-ray diffractograms}

The X-ray diffractograms of dialdehyde cellulose are depicted in Fig. 5.

With the successive cleavage of pyranose rings present in cellulose, a remarkable decrease in the crystallinity of cellulose can be observed from XRD pattern [6]. At higher oxidant concentrations, the two peaks of cellulose at $2 \theta$ values of $16^{\circ}$ and $22^{\circ}$ that correspond to 001 and 200 crystal planes in cellulose structure were merged into one peak at $18^{\circ}$. This is an indication that periodate oxidation results into a more amorphous cellulose whose peak value is usually observed around this point as reported by [21,26]. The amorphous peak at $2 \theta=18^{\circ}$ has also been used by numerous authors as a basis for the calculation of the empirical crystallinity index of cellulose using Segal's method [15, 26, 27, 33, 34]. This can also be explained by the fact that periodate oxidation leads to opening up of the glucopyranose ring in native cellulose leaving the amorphous domain intact while at the same time destroying the ordered packing of cellulose [29]. Moreover, the crystallinity of the fibers decreases with an increase in oxidation time as at higher oxidation time the material became completely amorphous hence the disappearance of the crystalline peaks often observed at $2 \theta=22^{\circ}$ as observed after $16 \mathrm{~h}$ oxidation [17].

\subsection{SEM and TEM micrographs}

The SEM and TEM micrographs of dialdehyde cellulose are depicted in Figs. 6 and 7 respectively.

From SEM micrographs, morphological changes induced by periodate oxidation were observed and as the degree of oxidation increased, the cellulose texture became more compact. Moreover, 2,3-dialdehyde cellulose comprised of a smooth surface that contained kinks and valleys and lacked visible fibers. Typically, microcrystalline cellulose generally has a rough surface which is an indication of lignin and hemicellulose removal during the pretreatment steps [17]. The formation of compact materials with smooth surfaces and no visible fibers has also been observed when Cladophora cellulose is oxidized and that higher degree of oxidation resulted to smoother and more compact structures [17].

The initial MCC samples mostly consisted of microfibrillar bundles with widths of a few nanometers and lengths ranging between $100 \mathrm{~nm}$ to a few micrometers typical of MCC [29]. Upon oxidation, the length distribution of the fibers drastically reduced to $20-160 \mathrm{~nm}$ (Fig. 7). This implies that periodate oxidation of the fibers led to a decrease in fiber length as TEM data for rice husk cellulose indicated that the fiber length range between 100 and $500 \mathrm{~nm}$ which was similar to what has been reported for microcrystalline cellulose $[21,33,35]$. The TEM observations confirmed the breakdown of the cellulose fibers into nanosized fibrils after the periodate oxidation leading to fragmentation of the cellulose fibrils during oxidation. However, it should be noted that shorter fibers length may be overstated because factors such as fiber curling and aggregation could influence the length of the measured fibers. Moreover, the image processing tool used may be subject to bias as not all fibers might be measured and as such it is rough approximation of fiber length. 

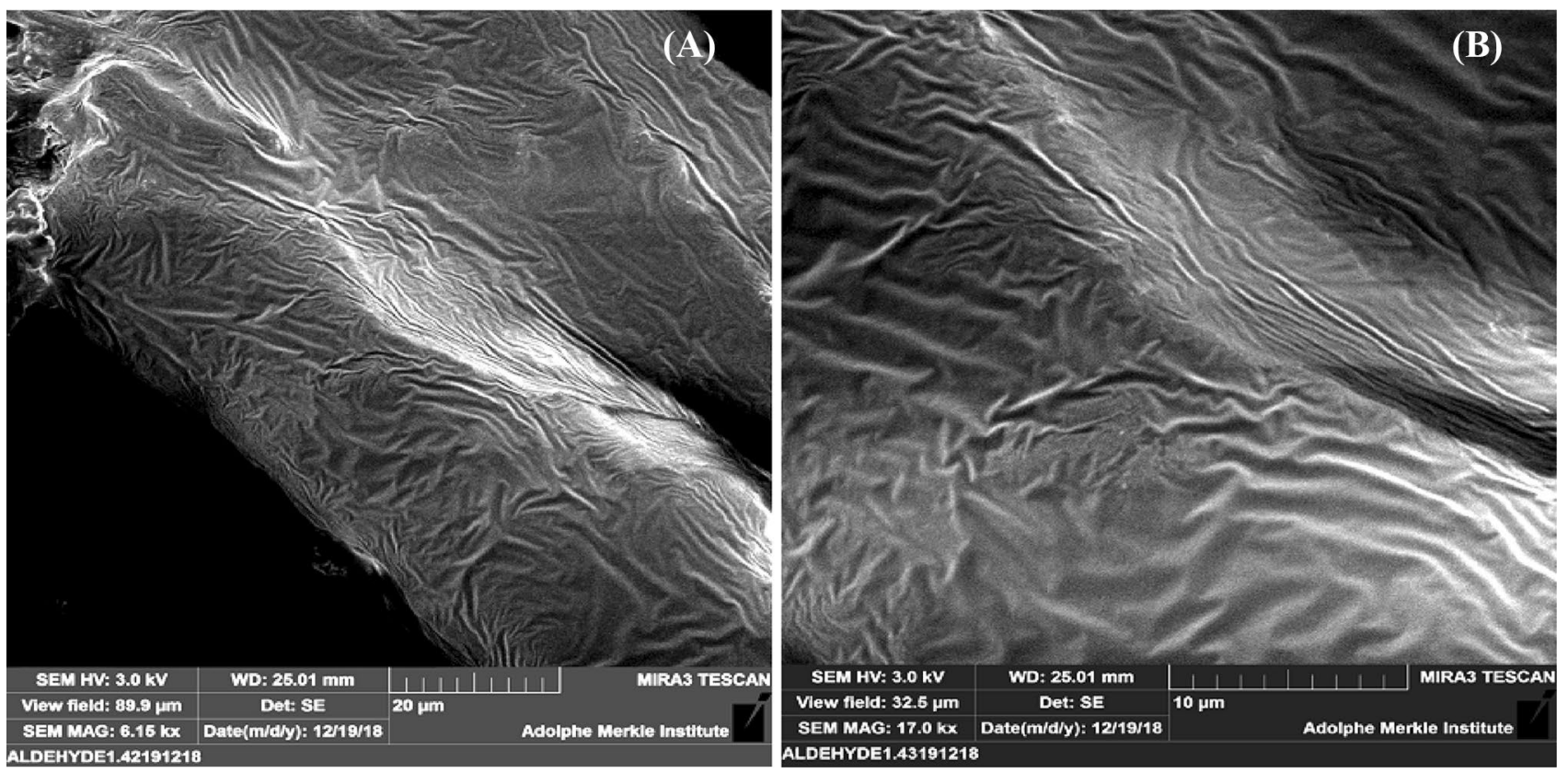

Fig. 6 SEM micrographs of oxidized cellulose under different magnifications

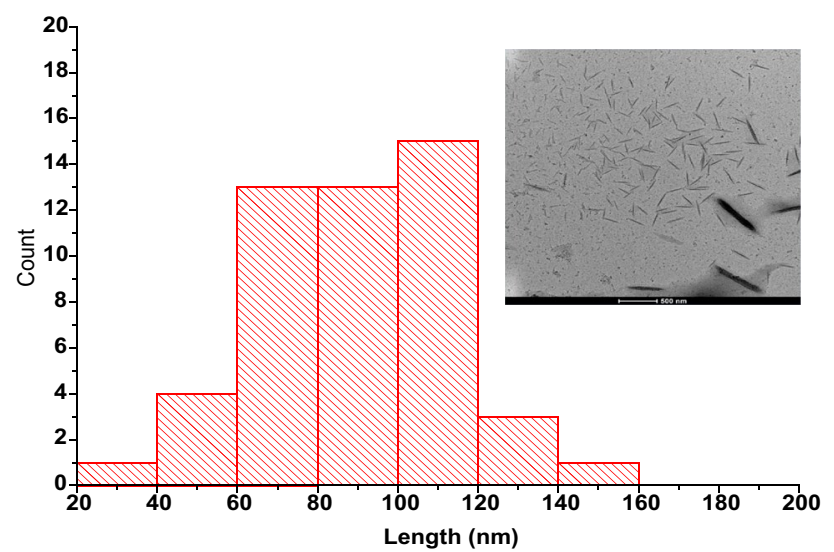

Fig. 7 TEM fiber length distribution of dialdehyde cellulose. Inset TEM micrographs of dialdehyde cellulose

\section{Conclusion}

Microcrystalline cellulose (MCC) was converted to 2,3-dialdehyde cellulose (DAC) by periodate oxidation of the fibers at elevated temperatures. Oxidation of cellulose resulted to subsequent decline in the crystallinity of cellulose as evidenced by XRD diffractograms and an increase in the aldehyde content of the oxidized fibers. From TEM images observed in this study, periodate oxidation reduced the size of the fibers as the resulting fibers had an average length between 20 and $200 \mathrm{~nm}$ as compared to un-oxidized fibers which have lengths between $100 \mathrm{~nm}$ to a few micrometers. The reduction of fiber length can be explained by the preferential oxidation of the amorphous domain and the chain scission that occured during periodate oxidation which leads to the release of broken fibrils. Moreover, solubility of cellulose in common solvents is very limited hence putting a restriction to its application as very few solvents can penetrate its structure. But through periodate oxidation, introduction of carbonyl functional groups at positions $C_{2}-C_{3}$ of cellulose opens a vast array of applications in which cellulose can be chemically crosslinked with amine functionalized groups in a Schiff's base reaction.

Acknowledgements The authors take this opportunity to acknowledge the National research fund NRF2014/2015, AFRICA-ai-JAPAN project JFY 2018/2019, Jomo Kenyatta University of Agriculture, and Technology for their financial support and access to facilities. The authors are also thankful to the federal commission of scholarships (FCS) for a one-year research fellowship at the University of Fribourg under Prof Katharina M. Fromm.

\section{Compliance with ethical standards}

Conflict of interest The authors declare that they have no conflict of interest.

\section{References}

1. Ciolacu DE, Suflet DM (2018) Cellulose-Based Hydrogels for Medical/Pharmaceutical Applications. Biomass as Renewable 
Raw Material to Obtain Bioproducts of High-Tech Value. Netherlands, Elsevier, Amsterdam, pp 401-439

2. Fürsatz $M$, Skog $M$, Sivlér $P$, Palm $E$, Aronsson $C$, Skallberg $A$, Greczynski G, Khalaf H, Bengtsson T, Aili D (2018) Functionalization of bacterial cellulose wound dressings with the antimicrobial peptide $\varepsilon$-poly-L-Lysine. Biomed Mater 13(2):025014

3. Hakkarainen T, Koivuniemi R, Kosonen M, Escobedo-Lucea $C$, Sanz-Garcia A, Vuola J, Tammela P, Makitie A, Yliperttula M (2016) Nanofibrillar cellulose wound dressing in skin graft donor site treatment. J Controlled Release 244:292-301

4. Hoglund, E. (2015). Production of Dialdehyde Cellulose and Periodate Regeneration: Towards feasible oxidation processes. Kalrstad: Master's Thesis, Department of Engineering and Chemical Sciences Kalrstad University

5. Kayra, N., \& Aytekin, A. Ö. (2019). Synthesis of Cellulose-Based Hydrogels: Preparation, Formation, Mixture, and Modification. Cellulose-Based Superabsorbent Hydrogels, 407-434

6. Plappert SF, Quraishi S, Pircher N, Mikkonen KS, Veigel S, Klinger KM, Potthast Rosenau T, Liebner FW (2018) Transparent, flexible, and strong 2, 3-dialdehyde cellulose films with high oxygen barrier properties. Biomacromol 19(7):2969-2978

7. Kimura S, Isobe N, Wada M, Kuga S, Ko JH, Kim UJ (2011) Enzymatic hydrolysis of chitosan-dialdehyde cellulose hydrogels. Carbohyd Polym 83(4):1850-1853

8. Liu XD, Nishi N, Tokura S, Sakairi N (2001) Chitosan coated cotton fiber: preparation and physical properties. Carbohyd Polym 44(3):233-238

9. Ruan CQ, Strømme M, Lindh J (2018) Preparation of porous 2, 3-dialdehyde cellulose beads crosslinked with chitosan and their application in adsorption of Congo red dye. Carbohyd Polym 181:200-207

10. Dong F, Li S (2018) Wound Dressings Based on Chitosan-Dialdehyde Cellulose Nanocrystals-Silver Nanoparticles: mechanical Strength. Antibacterial Activity and Cytotoxicity. Polymers 10(6):673

11. Nypelö T, Amer H, Konnerth J, Potthast A, Rosenau T (2018) Selfstanding nanocellulose janus-type films with aldehyde and carboxyl functionalities. Biomacromol 19(3):973-979

12. Chen $C$, Sun $W$, Yao W, Wang $Y$, Ying $H$, Wang $P$ (2018) Functional polymeric dialdehyde dextrin network capped mesoporous silica nanoparticles for $\mathrm{pH} / \mathrm{GSH}$ dual-controlled drug release. RSC Advances 8(37):20862-20871

13. Fitz, B. D., Looney, D., Craven, T. L., Dey, C., \& Garg, A. (2017). United States of America Patent No. 15/450,706

14. Hou Y, Wang X, Yang J, Zhu R, Zhang Z, Li Y (2018) Development and biocompatibility evaluation of biodegradable bacterial cellulose as a novel peripheral nerve scaffold. J Biomed Mater Res, Part A 106(5):1288-1298

15. Murigi MK, Madivoli ES, Mathenyu MM, Kareru PG, Gachanja AN, Njenga PK, Nowsheen G, Githira PN, Githua M (2014) Comparison of physicochemical characteristics of microcrystalline cellulose from four abundant Kenyan biomasses. Journal of Polymer and Textile engineering 1(2):53-63

16. Yang H, Sheikhi A, Van de Ven TG (2016) Reusable green aerogels from cross-linked hairy nanocrystalline cellulose and modified chitosan for dye removal. Langmuir 32:11771-11779

17. Lindh J, Ruan C, Strømme M, Mihranyan A (2016) Preparation of porous cellulose beads via introduction of diamine spacers. Langmuir 32(22):5600-5607

18. Alam MN, Christopher LP (2018) Natural Cellulose-Chitosan Crosslinked Superabsorbent Hydrogels with Superior Swelling Properties. ACS Sustainable Chemistry \& Engineering 6:8736-8742

19. Kristiansen KA, Potthast KA, Christensen BE (2010) Periodate oxidation of polysaccharides for modification of chemical and physical properties. Carbohyd Res 345(10):1264-1271
20. Lopez-Duran V, Hellwig J, Larsson PT, Wagberg L, Larsson PA (2018) Effect of Chemical Functionality on the Mechanical and Barrier Performance of Nanocellulose Films. ACS Applied Nano Materials 1(4):1959-1967

21. Errokh A, Magnin A, Putaux JL, Boufi S (2018) Morphology of the nanocellulose produced by periodate oxidation and reductive treatment of cellulose fibers. Cellulose 25(7):3899-3911

22. Yang $H$, Chen D, Van de ven TG (2015) Preparation and characterization of sterically stabilized nanocrystalline cellulose obtained by periodate oxidation of cellulose fibers. Cellulose 22(3):1743-1752

23. Ponce C, Chanona J, Garibay V, Palacios E, Calderon G, Sabo R (2013) Functionalization of Agave Cellulose Nanoparticles and its Characterization by Microscopy and Spectroscopy Techniques. Microsc Microanal 19(S2):200-201

24. Madivoli, E. S., Maina, E. G., Kairigo, P. K., Murigi, M. K., Nyangau, J. O., Kimani, P. K., \& Kipyegon, C. (2018). In vitro antioxidant and antimicrobial activity of Prunus africana (Hook. f.) Kalkman (bark extracts) and Harrisonia abyssinica Oliv. extracts (bark extracts): A comparative study. Journal of Medicinal Plants for Economic Development, 2(2), 1-9

25. Katata-Seru L, Moremedi T, Aremu OS, Bahadur I (2018) Green synthesis of iron nanoparticles using Moringa oleifera extracts and their applications: removal of nitrate from water and antibacterial activity against Escherichia coli. J Mol Liq 256:296-304

26. Poletto M, Ornaghi HL, Zattera AJ (2014) Native cellulose: structure, characterization and thermal properties. Materials 7(9):6105-6119

27. Ciolacu D, Ciolacu F, Popa VI (2011) Amorphous cellulose-structure and characterization. Cellul Chem Technol 45(1):13

28. Kian LK, Jawaid M, Ariffin H, Alothman OY (2017) Isolation and characterization of microcrystalline cellulose from roselle fibers. Int J Biol Macromol 103:931-940

29. Leguy J, Diallo A, Putaux JL, Nishiyama Y, Heux L, Jean B (2018) Periodate Oxidation Followed by $\mathrm{NaBH} 4$ Reduction Converts Microfibrillated Cellulose into Sterically Stabilized Neutral Cellulose Nanocrystal Suspensions. Langmuir 34(37):1 1066-11075

30. Zhang L, Ge H, Xu M, Cao J, Dai Y (2017) Physicochemical properties, antioxidant and antibacterial activities of dialdehyde microcrystalline cellulose. Cellulose 24(5):2287-2298

31. Li H, Wu B, Mu C, Lin W (2011) Concomitant degradation in periodate oxidation of carboxymethyl cellulose. Carbohyd Polym 84(3):881-886

32. Mou K, Li J, Wang Y, Cha R, Jiang X (2017) 2, 3-Dialdehyde nanofibrillated cellulose as a potential material for the treatment of MRSA infection. Journal of Materials Chemistry B 5(38):7876-7884

33. Besbes I, Villar MR, Boufi S (2011) Nanofibrillated cellulose from alfa, eucalyptus and pine fibres: preparation, characteristics and reinforcing potential. Carbohyd Polym 86(3):1198-1206

34. Segal LG, Creely JJ, Martin AE Jr, Conrad CM (1959) An empirical method for estimating the degree of crystallinity of native cellulose using the X-ray diffractometer. Text Res J 29(10):786-794

35. Cerqueira JC, Penha JD, Oliveira RS, Guarieiro LN, Melo PD, Viana JD, Machado BA (2017) Production of biodegradable starch nanocomposites using cellulose nanocrystals extracted from coconut fibers. Polimeros 27(4):320-329

Publisher's Note Springer Nature remains neutral with regard to jurisdictional claims in published maps and institutional affiliations. 